\title{
The risk of cardiovascular events based on the Framingham criteria in Adults Living in Mashhad (Iran)
}

Zeinab Shateri Amiri ${ }^{1}$, Mohammad Khajedaluee ${ }^{2}$, Abdolrahim Rezaii ${ }^{3}$, Maliheh Dadgarmoghaddam ${ }^{4}$

${ }^{1}$ MD, Resident of Community Medicine, Community Medicine Department, Faculty of Medicine, Mashhad University of Medical Sciences, Mashhad, Iran

${ }^{2}$ MD, Professor of Community Medicine, Community Medicine Department, Faculty of Medicine, Mashhad University of Medical Sciences, Mashhad, Iran

${ }^{3}$ Ph.D., Associate Professor, Immunology Research Center, Inflammation and Inflammatory Diseases Division, Faculty of Medicine, Mashhad University of Medical Sciences, Mashhad, Iran

${ }^{4}$ MD, Assistant Professor of Community Medicine, Community Medicine Department, Faculty of Medicine, Mashhad University of Medical Sciences, Mashhad, Iran

\section{Type of article: Original}

\begin{abstract}
Background and aim: Cardiovascular diseases are a problem in low- and middle-income countries, such as Iran. The present research was performed to identify risk factors contributing to cardiovascular diseases and their distributions among the adult population of Mashhad (Iran) using the Framingham criteria.

Methods: This cross-sectional population-based study performed in 2015 on 2,976 adults living in Mashhad (Iran) using Stratified cluster-random sampling method. Demographic information was acquired by surveyors in the research team using a checklist and referring to a medical laboratory for laboratory assessments. The 10-year risk of cardiovascular diseases for the participants was calculated using the Framingham criteria and was classified into three classes: low risk $(<10 \%)$, intermediate risk $(10-20 \%)$, and high risk $(>20 \%)$. The analysis was done by SPSS Version 11.5 by using the Independent-samples t-test, Kruskal-Wallis, and analysis of variance (ANOVA).

Results: A total of 2,978 participants aged 16-90 participated in our cross-sectional study with an average age of $43.5 \pm 14.7$ years. Total risk scores among men and women were $7.29 \pm 6.3$ and $5.8 \pm 6.03$, respectively. Compared to women, men exhibited a significantly higher risk of cardiovascular diseases $(\mathrm{p}<0.001)$. Average heart age among men and women was estimated at $50.37 \pm 18.7$ and $48.8 \pm 17.0$ respectively, i.e. significantly older heart age was obtained for men compared to women $(\mathrm{p}<0.001)$.

Conclusion: According to this study, men are at a great risk of cardiovascular events, so we should develop our screening and educational program especially for this population.

Keywords: Cardiovascular diseases, Framingham study, Risk factors, Prevention
\end{abstract}

\section{Introduction}

Cardiovascular diseases are the most common cause of death in the world and the most important cause of disability and decreased quality of life (1-3). Moreover, it is the leading cause of disability and mortality in Iran, with $50 \%$ of deaths being due to cardiovascular problems (4). Annually, 17.7 million people die of cardiovascular diseases worldwide, accounting for $31.1 \%$ of all deaths. Further, $80 \%$ of deaths are due to heart attacks (coronary artery diseases) and stroke (brain blood vessel problems), more than $75 \%$ of which occur in low and middle-income countries (5). Some studies have reported an early emergence of cardiovascular diseases in these countries, the frequency of which will increase in the coming years (6). Furthermore, increased burden of disease is one of the

\section{Corresponding author:}

Assistant Professor Dr. Maliheh Dadgarmoghaddam, Community Medicine Department, Faculty of Medicine, Mashhad University of Medical Sciences, Mashhad, Iran. Tel: +98.5138002398, Email: Dadgarmm@mums.ac.ir

Received: May 21, 2018, Accepted: August 05, 2018, Published: August 2018

iThenticate screening: August 07, 2018, English editing: August 13, 2018, Quality control: August 15, 2018

This article has been reviewed / commented by five experts

Ethics approval: Mashhad University of Medical Sciences (Ref: IR.MUMS.FM.REC.1396.18)

(C) 2018 The Authors. This is an open access article under the terms of the Creative Commons Attribution-NonCommercialNoDerivs License, which permits use and distribution in any medium, provided the original work is properly cited, the use is non-commercial and no modifications or adaptations are made. 
major challenges facing development in such countries (7). Various factors have contributed to this disease, and more than two hundred and fifty risk factors have been identified for coronary heart diseases (8). Some risk factors include aging $(9,10)$, male gender $(11,12)$, high blood pressure $(13,14)$, diabetes mellitus $(15-17)$, smoking $(18-21)$ and lipid disorders (22-24). Aging, male gender, family history, and genetic factors are not moderating factors; however, other factors are moderating and can be addressed through adopting an appropriate strategy to prevent and treat ischemic heart diseases and performing the required interventions (25). The results of various epidemiological studies in the developed countries reveal that the mortality rate of coronary heart diseases has decreased over the last three decades, thanks to a better understanding and control of such risk factors $(8,23)$. Despite the lack of accurate statistics in Iran, there is strong evidence indicating that the incidence of coronary heart diseases and the resulting deaths has significantly increased (23). According to the World Health Organization, in 2005, $41.3 \%$ of all deaths in Iran were caused by cardiovascular diseases. It is also predicted that this rate will increase up to $44.8 \%$ by 2030 (26).

In order to assess the risk level of cardiovascular diseases, diagnostic instruments are used to identify individuals at risk. One of these instruments is the Framingham criteria, which estimates the true risk level based on the Framingham Cohort study. This study began in 1948 with 5,209 adult subjects to identify the common factors that contribute to cardiovascular diseases (27), by using age-relevant information, total cholesterol ratio, HDL, systolic blood pressure, history of smoking, and history of diabetes mellitus in order to predict the risk of developing cardiovascular diseases over the next 10 years $(28,29)$. This instrument has been effective in predicting and ranking the level of cardiovascular risk in many parts of the world (30). It could also be effective in quantifying the risk and ranking the level of risk in Iranian adults (31). According to the findings, the relationship between ischemic heart disease and its risk factors is partially associated with race and geographical area; therefore, the investigation of the risk factors as well as the assessment of CHD risk level in populations of different regions of Iran seems to be of essence. This study was performed in the city of Mashhad in which the Framingham criteria were adopted to determine the risk of ischemic heart diseases among Mashhad's adult population in order to estimate the 10 -year risk level for the target population.

\section{Material and Methods}

\subsection{Research design and selection criteria}

The 2,978 participants were studied in this cross-sectional population-based study in Mashhad (age $\geq 16$ years: based on the epidemiological studies that demonstrate some decrease in the average age at which cardiovascular incidents especially heart ischemia occur in the Iranian population) in 2015. The following were set as the Inclusion criteria:

1) All of those whose complete set of demographic and socioeconomic information was available.

2) All of those whose serum samples were available for determining lipid profiles.

3) All people over 16 years of age

4) All of those who have residence in Mashhad

Exclusion criteria were:

1) Individuals with incomplete checklists or laboratory samples.

2) Non-consent to participate in any stages of the study.

\subsection{Sampling}

This sample was taken out of a Chronic Kidney Disease prevalence study in 2015 (a study that was performed by researchers to collect data of the Mashhad population) via stratified cluster-random sampling method. The sample size was determined for the main study and we used the data bank data for this study. The sample size was estimated for assessment of chronic kidney disease according to these assumptions: $\alpha=0.05, \beta=0.2$, and $p=0.92$ (by using this formula: $\mathrm{n}=\mathrm{Z}^{2} \mathrm{pq} / \mathrm{d}^{2}$ ). The sample size was estimated to be 2,700 by considering $30 \%$ attrition bias and multiplying by three for the clustering design. The city of Mashhad was divided into 5 districts based on health centers. Center 4 was excluded from the study due to the non-constant cessation population and the other 4 sites were sampled.

\subsection{Data collection}

The main objective of the study was explained to the participants and informed consent was taken. Subsequently, surveyors in the research team filled a checklist of the participants' demographic, socioeconomic and lifestyle information before referring the subjects to physicians in the research team and related health centers for health status assessment. Once visited by the physician of the urban health centers, subjects were submitted to the laboratory of the center where their blood samples were collected and immediately sent to the sample collection center of the research program. The samples were collected by staff trained in urban health centers, and were stored 
in a refrigerator at -80 centigrade before being sent to the reference laboratory for measuring fasting blood sugar (FBS), total serum cholesterol, LDL and HDL, and triglyceride levels.

\subsection{The method of calculation}

The cardiovascular disease risk score, 10-year risk of cardiovascular incidents, and heart age of the subjects were calculated using the Framingham criteria (28). Given that several observations and clinical studies have suggested some decrease in the average age at which cardiovascular incidents (heart ischemia, in particular) may occur among the Iranian population, (leading to an increasingly higher number of clinical cases where heart attacks occurring at ages younger than 30 being observed), the present research calculated and classified the risk of cardiovascular diseases based on the Framingham criteria in two age groups, namely older than 16 and older than 30 (considering access to subjects). In the first stage, the subjects were scored separately for each gender, their age, total cholesterol, smoking, HDL level, systolic blood pressure, and diabetes according to the Framingham criteria (28). For this purpose, subjects with FBS higher than $126 \mathrm{mg} / \mathrm{dl}$ and per-day smoking of at least 1 cigarette or 1 pass of hookah were considered as diabetics and smokers, respectively. The subjects' blood pressure was determined according to standard procedures and criteria to be followed prior to blood pressure determination. This was done using sphygmomanometers, which were calibration-controlled on a daily basis by the physicians in the research team. A blood pressure above $140.90 \mathrm{mmHg}$ was considered as high blood pressure. Blood pressure, total serum cholesterol, and age of the subjects were categorized based on the Framingham criteria (28). Effects of risk factors are cumulative, and the relationship between the factors and CHD has been quantitatively evaluated in a study by Framingham (28); accordingly, based on the risk of developing cardiovascular diseases in the coming 10 years, individuals can be classified into three classes: low risk $(<10 \%)$, intermediate risk $(10-20 \%)$, and high risk $(>20 \%)$ (28). In the second stage, heart age of the subjects was determined based on their total score. Finally, the population was categorized into different levels based on the attained heart age and total score, based on which, one could determine the percentage of the population who needed to take particular actions. The collected data was analyzed using the Framingham criteria manual (28).

\subsection{Ethical considerations}

The research was approved by the Research Council of Mashhad University of Medical Sciences and the Research Ethics Committee (Ref: IR.MUMS.fm.REC.1396.18). Written informed consent was obtained from all the participants and they were free to leave the study at any stage. All the collected data were secured as confidential, and the results were presented in general form without providing any personal identity. The participants' test results were sent to them and follow-up recommendations were provided to them by the physicians of the research team. The studied data in the present research were taken from a CKD prevalence study on the adult population of Mashhad.

\subsection{Statistical analysis}

Data analysis was performed by SPSS Software ver. 11.5 (SPSS Inc., Chicago, Illinois, USA). Descriptive results were obtained using measures of central tendency dispersion, and frequency distribution. Continuous variables were tested using the Independent-samples t-test, ranked variables were analyzed using Kruskal-Wallis, and average values were compared using analysis of variance (ANOVA) based on the type of the variables and after checking the distribution of the quantitative variables. Qualitative variables were considered with Chi-square test and a significance level was determined as 0.05 .

\section{Results}

In this cross-sectional study, performed on 2,978 patients at ages ranging from 16 to 90 years, there were 1,930 $(64.9 \%)$ women and $1,044(35.1 \%)$ men with an average age of $43.5 \pm 14.7$ years. The average age of the men was significantly higher than that of the women $(\mathrm{p}<0.001)$, most of the patients were married $(84.7 \%)$, the most frequent academic level was primary school (31.4\%), $85.7 \%$ of the women were housewives, and $49.8 \%$ of the men were self-employed, and the differences between the two genders in marital status $(p<0.001)$, level of education $(\mathrm{p}<0.001)$, and occupation $(\mathrm{p}<0.001)$ were significant. Furthermore, in the evaluation of the risk and disease factors, $8.4 \%$ of the patients were smokers, where the ratio was $14.9 \%$ in the men and $4.9 \%$ in the women, and the difference between the two genders was significant $(\mathrm{p}<0.001)$. All the information on the demographic characteristics appears in Table 1.

In the experimental investigations and clinical visits, $22.1 \%$ of the patients had high blood pressure, which was significantly more frequent in men $(\mathrm{p}<0.001)$. Furthermore, $8.3 \%$ of the patients had diabetes, which included 
$11.7 \%$ of the men and $6.5 \%$ of the women, a statistically significant difference between the two genders $(\mathrm{p}<0.001)$. There was no significant difference between the men and the women in average blood cholesterol $(\mathrm{p}=0.62)$, but there was a statistically significant difference between the two genders in average triglyceride, LDL, and HDL (Table 2). Total risk score in the population over 16 years was calculated based on the Framingham algorithm given different risk factors in terms of gender. Total risk score was calculated as 7.29 \pm 6.3 in the men and $5.8 \pm 6.03$ in the women. Total risk of cardiovascular disease was statistically significantly higher in the men than in the women $(\mathrm{p}<0.001)$; being more severe in men between 55 and 59, and between 70 and 74 years old in women.

Table 1. Demographic characteristics

\begin{tabular}{|c|c|c|c|c|c|c|c|c|}
\hline \multirow{2}{*}{\multicolumn{2}{|c|}{ Variable }} & \multicolumn{2}{|l|}{ Man } & \multicolumn{2}{|c|}{ Woman } & \multicolumn{2}{|c|}{ Total } & \multirow[t]{2}{*}{$\mathrm{p}$-value } \\
\hline & & $\mathrm{n}$ & $\%$ & $\mathrm{n}$ & $\%$ & $\mathrm{n}$ & $\%$ & \\
\hline \multicolumn{2}{|l|}{ Sex } & 1044 & 35.1 & 1930 & 64.9 & 2974 & 100 & \\
\hline \multicolumn{2}{|c|}{ Age average (year); Mean \pm SD } & \multicolumn{2}{|c|}{$49.10 \pm 15.7$} & \multicolumn{2}{|c|}{$42.12 \pm 13.8$} & \multicolumn{2}{|c|}{$43.5 \pm 14.7$} & 0.001 \\
\hline \multirow[t]{4}{*}{ Marital status } & Single & 118 & 11.4 & 166 & 8.7 & 284 & 9.6 & \\
\hline & Married & 909 & 87.6 & 1594 & 83.2 & 2503 & 84.7 & \\
\hline & Widowed & 8 & 0.8 & 142 & 7.4 & 150 & 5.1 & \\
\hline & Divorced & 3 & 0.3 & 14 & 0.7 & 17 & 0.6 & \\
\hline \multirow[t]{6}{*}{ Education } & Illiterate & 83 & 8.1 & 296 & 15.4 & 379 & 12.8 & \multirow[t]{6}{*}{0.001} \\
\hline & Primary & 306 & 29.7 & 628 & 15.4 & 034 & 31.6 & \\
\hline & High School & 214 & 20.8 & 313 & 16.3 & 528 & 17.9 & \\
\hline & High School diploma & 231 & 22.8 & 484 & 25.2 & 719 & 24.2 & \\
\hline & Associate degree & 78 & 7.6 & 76 & 4 & 152 & 5.2 & \\
\hline & Bachelor's or higher & 119 & 11.5 & 125 & 6.5 & 244 & 8.3 & \\
\hline \multirow[t]{6}{*}{ Occupation } & Unemployed & 119 & 11.7 & 51 & 2.7 & 170 & 5.8 & \multirow[t]{6}{*}{0.001} \\
\hline & Clerk & 208 & 20.5 & 86 & 4.5 & 295 & 10.1 & \\
\hline & Worker & 127 & 12.5 & 12 & 0.6 & 139 & 4.8 & \\
\hline & Self-employed & 505 & 49.8 & 43 & 2.3 & 548 & 18.8 & \\
\hline & Student & 50 & 4.9 & 80 & 4.2 & 130 & 4.4 & \\
\hline & Housewife & 5 & 0.5 & 1634 & 85.7 & 1640 & 55.1 & \\
\hline \multirow[t]{4}{*}{ Health district } & No. 1 & 341 & 32.7 & 670 & 34.7 & 1012 & 34 & \multirow[t]{4}{*}{0.001} \\
\hline & No. 2 & 173 & 16.6 & 288 & 14.9 & 461 & 15.5 & \\
\hline & No. 3 & 353 & 33.8 & 496 & 25.7 & 850 & 12.6 & \\
\hline & No. 5 & 177 & 17 & 476 & 24.7 & 653 & 21.9 & \\
\hline \multirow[t]{2}{*}{ Smoking } & Yes & 154 & 14.9 & 94 & 4.9 & 250 & 8.4 & \multirow[t]{2}{*}{0.001} \\
\hline & No & 888 & 85.1 & 1836 & 95.1 & 2726 & 91.6 & \\
\hline
\end{tabular}

Table 2. Lipid profile average and diabetes and high blood pressure frequency in the population under investigation

\begin{tabular}{|l|l|l|l|l|l|}
\hline \multirow{2}{*}{ Variable } & Man & \multicolumn{3}{|l|}{ Woman } & \multirow{2}{*}{-value } \\
\cline { 2 - 6 } & Mean & SD & Mean & SD & \\
\hline Cholesterol (mg/dL) & 182.05 & 37.4 & 181.17 & 39.2 & 0.62 \\
\hline Triglyceride (mg/dL) & 156.05 & 89.8 & 132.31 & 93.9 & 0.001 \\
\hline LDL (mg/dL) & 106.27 & 28.7 & 109.44 & 27.3 & 0.015 \\
\hline HDL (mg/dL) & 43.28 & 10.9 & 44.40 & 11.0 & 0.028 \\
\hline Diabetes + & 83 & 11.7 & 87 & 6.5 & 0.001 \\
\hline Hypertension + & 264 & 25.9 & 376 & 20 & 0.001 \\
\hline
\end{tabular}

Heart age was calculated for the patients based on the total risk scores estimated for the two genders. Average heart age was estimated as $50.37 \pm 18.7$ years for the men and as $48.8 \pm 17.0$ for the women. The men's heart age was significantly higher than the women's $(\mathrm{p}<0.001)$. Heart age was significantly higher than chronological age in the women's group ( $\mathrm{p}=0.002)$, while chronological age was slightly higher than heart age $(\mathrm{p}=0.05)$ in the men's group. Based on the participants' heart age, their ten-year risk of cardiovascular disease were calculated in terms of the Framingham criteria, and the subjects were classified at the three levels of low-risk $(<10 \%)$, intermediate-risk $(10$ $20 \%$ ), and high-risk $(>20 \%)$. In the population with an age range of 16 to 90 years, $82.9 \%$ were estimated to be at the low-risk level, $10.1 \%$ at intermediate-risk, and $6.8 \%$ at high risk. Risk was calculated separately for the age 
group below 30 years (680 patients), where all were estimated as low-risk (100\%). Recalculation of risk level disregarding this age group led to estimation of $77.8 \%$ at the low-risk level, $13.4 \%$ at the intermediate-risk level, and $8.8 \%$ at high risk (Table 3 ).

In both population groups under investigation, the intermediate- and high-risk levels were statistically significantly higher in men than in women $(\mathrm{p}<0.001)$. Since the entire population below 30 years had lower risk levels, the relationship between risk level and demographic characteristics was investigated further only for the population over 30 years of age (Table 4). There was a statistically significant difference between the four health centers in terms of the frequency of risk levels (low, intermediate, or high) $(\mathrm{p}<0.001)$. The highest risk level frequencies were estimated to have occurred in health centers 1 and 3, and health center 2 had the lowest risk level frequencies. The risk levels in health center 1 exhibited an even trend.

The relationship between academic degree and heart risk level was statistically significant $(\mathrm{p}<0.001)$. The highest risk level frequency was observed in the primary academic group, and the lowest levels in the patients with an associate and bachelor's degree and higher academic groups. There was a statistically significant relationship between heart risk level and occupation status $(p<0.001)$. The highest frequencies were observed among housewives at the low- and intermediate-risk levels and the unemployed at the high-risk level. There was a statistically significant relationship between ten-year heart risk level and marital status $(\mathrm{p}<0.001)$. The highest ten-year heart risk level frequencies concerned the married patients, and the lowest pertained to the divorced.

Table 3. Calculation of ten-year CVD risk based on two age groups

\begin{tabular}{|c|c|c|c|c|c|}
\hline Age group & Gender & $\begin{array}{l}\text { Low-risk } \\
(<10 \%)\end{array}$ & Intermediate-risk (10-19\%) & High-risk (> 20\%) & $\mathrm{p}$-value \\
\hline \multirow[t]{3}{*}{ Population over 16 years } & Men & 67.8 & 16.8 & 15.4 & \multirow[t]{3}{*}{$<0.001$} \\
\hline & Women & 91.0 & 6.8 & 2.1 & \\
\hline & Total & 82.9 & 10.3 & 6.8 & \\
\hline \multirow[t]{3}{*}{ Population over 30 years } & Men & 60.0 & 20.9 & 19.2 & \multirow[t]{3}{*}{$<0.001$} \\
\hline & Women & 88.1 & 9.1 & 2.8 & \\
\hline & Total & 77.8 & 13.4 & 8.8 & \\
\hline
\end{tabular}

Table 4. Relationship between the demographic characteristics and ten-year cardiovascular risk level

\begin{tabular}{|c|c|c|c|c|c|c|c|c|}
\hline \multirow{2}{*}{\multicolumn{2}{|c|}{ Variable }} & \multicolumn{2}{|c|}{ Low-risk } & \multicolumn{2}{|c|}{ Intermediate-risk } & \multicolumn{2}{|c|}{ High-risk } & \multirow[t]{2}{*}{ p-value } \\
\hline & & $\mathrm{n}$ & $\%$ & $\mathrm{n}$ & $\%$ & $\mathrm{n}$ & $\%$ & \\
\hline \multirow[t]{4}{*}{ Health district } & No. 1 & 634 & 35.6 & 107 & 34.9 & 72 & 35.6 & \multirow[t]{4}{*}{0.002} \\
\hline & No. 2 & 265 & 14.9 & 49 & 16.0 & 27 & 13.4 & \\
\hline & No. 3 & 494 & 27.8 & 106 & 34.5 & 71 & 35.1 & \\
\hline & No. 5 & 387 & 21.7 & 45 & 14.7 & 32 & 15.8 & \\
\hline \multirow[t]{6}{*}{ Education } & Illiterate & 222 & 12.6 & 86 & 28.3 & 62 & 31 & \multirow[t]{6}{*}{0.001} \\
\hline & Primary & 648 & 36.7 & 123 & 40.5 & 75 & 37.5 & \\
\hline & High School & 333 & 18.8 & 37 & 12.2 & 19 & 9.5 & \\
\hline & High School diploma & 380 & 21.5 & 26 & 8.6 & 28 & 14 & \\
\hline & Associate degree & 68 & 3.8 & 11 & 3.6 & 10 & 5 & \\
\hline & Bachelor's or higher & 117 & 6.6 & 21 & 6.9 & 6 & 3 & \\
\hline \multirow[t]{6}{*}{ Occupation } & Unemployed & 33 & 1.9 & 37 & 12.4 & 49 & 25.7 & \multirow[t]{6}{*}{0.001} \\
\hline & Clerk & 170 & 9.7 & 57 & 19.1 & 43 & 22.5 & \\
\hline & Worker & 83 & 4.7 & 20 & 6.7 & 11 & 5.8 & \\
\hline & Self-employed & 310 & 17.7 & 63 & 21.1 & 51 & 12 & \\
\hline & Student & 9 & 0.5 & 0 & 0 & 0 & 0 & \\
\hline & Housewife & 1150 & 65.5 & 122 & 40.8 & 37 & 19.4 & \\
\hline \multirow[t]{4}{*}{ Marital status } & Single & 37 & 2.1 & 3 & 1 & 5 & 2.5 & \multirow[t]{4}{*}{0.001} \\
\hline & Married & 1629 & 92.2 & 258 & 84.3 & 177 & 88.9 & \\
\hline & Widowed & 89 & 5 & 43 & 14.1 & 15 & 7.5 & \\
\hline & Divorced & 11 & 0.6 & 2 & 0.7 & 2 & 1 & \\
\hline
\end{tabular}




\section{Discussion}

Cardiovascular diseases are a problem in low- and middle-income countries, such as Iran. The relationship between ischemic heart disease and its risk factors is partially associated with race and geographical region (32). In this study, all of the younger-than-30 subjects were estimated to have low $(<10 \%) 10$-year risk of cardiovascular diseases; this may indicate that, in the studied population, the factors contributing to the determination of 10 -year risk of cardiovascular diseases are still uncommon among individuals of this age group. Of the studied population of individuals older than 30,77.8\%, 13.4\%, and 8.8\% were recognized with low, intermediate, and high risks of the diseases, respectively. Compared to a similar study performed on a 40-65 years-old population of Asians (based on NHMS information, 2006) $48 \%, 29 \%$, and $23 \%$ of the subjects were recognized with low, intermediate, and high risks of the diseases, respectively (33), and according to another study performed based on the data from the surveillance system on risk factors for non-communicable diseases among the entire 25-64 year-old population of Iran in $2011,51.6 \%, 25.8 \%$, and $22.6 \%$ were found to be engaged with low, intermediate, and high risks of the diseases, respectively (34). The percentages of the subjects exposed to intermediate and high risks of cardiovascular diseases were estimated to be higher than of those in the present study. Given the fact that the recent study has differed from the time of study and the age range, this could indicate lower abundance of risk factors among the individuals examined in the present study and differences in lifestyles.

Accordingly, investigating the abundance of risk factors among the population examined in the present study, it was found that diabetes $(8.3 \%)$, smoking $(8.4 \%)$, and high blood pressure $(22.1 \%)$ were the most significant risk factors. In the study on the Asian population, the corresponding percentages were $17.1 \%, 20 \%$, and $54.9 \%$, respectively, indicating a generally higher abundance of risk factors (33). However, similar to the present study, high-blood pressure was the most abundant risk factor among the Asian population (33). Comparing the distribution of risk factors related to sugar and lipid across other areas in the country, it found lower levels of risk factors in our study population than the studied population in Tehran (29). However, in comparison with the same study in Isfahan (35) and Qazvin (36), the risk level of hypertension was higher. Prevalence of diabetes and smoking as risk factors was lower among the population examined in the present study, as compared to those in other regions in Iran, while high-blood pressure was estimated to be slightly more prevalent among the subjects of the present study. It is worth noting that the cited studies were performed in different years, and completely different geological conditions greatly contribute to dominant lifestyle.

As far as gender is concerned, the present study indicated relatively high percentages of intermediate and high risks for men. Other studies such as the state-wide study (34) and those performed in Isfahan (35), Qazvin (36), Mazandaran (37), Hamedan (38) and Asia (33), and also an American population (based on NHANES data during 1999-2002) (39) show similar results, implying that the male gender itself serves as a risk factor. Even though among the population studied in the present research, the studied men were, on average, older than the studied women, the resultant risk scores for men in different age groups were always higher than of those for the corresponding women. As such, the higher frequencies of individuals engaged with intermediate and high risks of the diseases among men with higher prevalence of risk factors (e.g. smoking, diabetes, high blood pressure, hyperlipidemia) can be indicative of unhealthy lifestyle, less than enough primary health care, or even less frequent contact with these centers, which are definitely effective on health knowledge of these individuals (40). As such, importance of preventive and purposive care programs and modifications to men's lifestyle should be emphasized.

Frequency of individuals engaged with high risk of the diseases increased with age among individuals of either gender. However, the increase in the frequency was observed 5 years earlier among men rather than women. This increased risk in men of lower ages was also pointed out in the study on the Asian population (33), which can be attributed to progression of atherosclerotic lesions of coronary arteries with age (41). According to Framingham criteria, for each 10 years increase in age, risk of cardiovascular diseases increases two units in population (42). Furthermore, thanks to the estrogen hormone, women enjoy a higher level of protection against cardiovascular diseases $(43,44)$, resulting in a delay of 10 years in progression of the diseases, as compared to men (41). In our research, trend of increase in the risk among elderlies (older than 65 years) was once more indicative of higher risk levels for men. In contrast, according to the sugar and lipid study performed in Tehran, older women exhibited higher risk levels than older men (45). Albeit, it should be mentioned that, in the present study, with increasing the age, the increase in the number of women at high risk of the diseases was sharper among 50-54 and 60-64 age groups, as compared to the men in the same age groups; this could be justified by the reduced protective effect of estrogen. Increased heart age of women relative to their calendar age and the opposite trend in men were also remarkable in the present study. Which requires more study. 
In the meantime, some recent research works have predicted equal risks of cardiovascular diseases for men and women during the coming decades $(45,46)$. Among the population studied in the present research, women were often undereducated, housewives, of low health knowledge and of poor socioeconomic position (representing a set of conditions including income level, education level, job, and personal assets), which could act as factors contributing to an inactive lifestyle, and failure to go on a suitable diet and other non-evaluated factors such as overweight among women could be significant factors contributing to emergence of chronic diseases such as cardiovascular disorders. In the present research, the lower the education level, the higher the risk level was. The highest 10-year risk of cardiovascular diseases was observed among illiterates, as was the case in the similar studies performed in United States (47) and Europe (48). Therefore, increasing women's awareness (who serve as mothers at the same time) can significantly contribute to the choice of a healthy lifestyle by all members of the community.

Considering the districts covered by different health centers, the population served by health centers 1 and 3 in Mashhad exhibited the highest frequencies of individuals at different risk levels, with a uniformly increasing trend in the 10-year risk of cardiovascular diseases. The lowest relative frequencies of individuals at different risk levels were observed in health center 2 . This could be explained by public health position and demographic characteristics and lifestyle of the individuals covered by different health centers; the health care services provided by different centers could be another contributing factor. Health center 2 covers low-income classes with lower socio-economic positions, so that their generally more active jobs (most of them are labors or servants) and low-meat diet can be referred to as reasons behind low levels of risk among this population.

Levels of risk of cardiovascular diseases were found to be significantly related to job type. Accordingly, unemployed subjects exhibited the highest risk of cardiovascular diseases. In a study by Iker et al., lack of job security was shown to be associated with cardiovascular diseases in women (49), indicating that paying attention to the unemployment rate in a community will reduce the risk of cardiovascular diseases. Marriage serves as an important social factor affecting health status and fatality rate. In the present study, the highest risk levels were observed among married subjects. This was opposite to other studies where increased fatalities were reported among divorced men, rather than those who were married, so that marriage was recognized as a protective factor (50). In a study in Japan, increased number of fatalities due to cardiovascular diseases was higher among men who were never married (51). In our society, however, marriage seems to bring about increased social and economic responsibilities and hence stress factors in the workplace, keeping it from serving as a protective factor for individuals' health.

\section{Limitations and strengths}

Key positive features of this study include large sample size, accuracy of experimental measurements and medical examinations, and the multi stage sampling method. One of the limitations of this study was the fact that, some of the information used here was obtained via self-reporting, which is known to be strongly biased by the participants. Furthermore, it seems that frequency of smoking and using drugs is underreported, which could be a result of the social desirability bias.

\section{Conclusions}

In the present research, the studied population exhibited high frequency of high-blood pressure, which can be greatly prevented by controlling the risk factors and modifying lifestyle. By considering an increased level of cardiovascular risk factors for men, it is necessary to expand our prevention strategy and carry out more educational programs concerning heart heath. Moreover, the following actions are recommended to change lifestyle: holding training programs, promoting healthy foods, controlling blood pressure, emphasizing the significance of giving up smoking, avoiding stress, and highlighting the importance of exercising. It is recommended to follow up the population in a longitudinal study and observe the risk level changes in upcoming years.

\section{Acknowledgments:}

Special thanks to the Deputy of Research at Mashhad University of Medical Sciences for financial support. This research is based on the Dr. Zeinab Shateri Amiri dissertation to fulfill the requirements for graduating for a specialist MD degree.

\section{Conflict of Interest:}

There is no conflict of interest to be declared. 


\section{Authors' contributions:}

All authors contributed to this project and article equally. All authors read and approved the final manuscript.

\section{References:}

1) Thayer JF, Yamamoto SS, Brosschot JF. The relationship of autonomic imbalance, heart rate variability and cardiovascular disease risk factors. International journal of cardiology. 2010; 141(2): 122-31. doi: 10.1016/j.ijcard.2009.09.543.

2) Members WG, Benjamin EJ, Blaha MJ, Chiuve SE, Cushman M, Das SR, et al. Heart disease and stroke statistics - 2017 update: a report from the American Heart Association. Circulation. 2017; 135(10): e146. doi: 10.1161/CIR.0000000000000485.

3) Shahraz S, Forouzanfar MH, Sepanlou SG, Dicker D, Naghavi P, Pourmalek F, et al. Population health and burden of disease profile of Iran among 20 countries in the region: from Afghanistan to Qatar and Lebanon. Arch Iran Med. 2014; 17(5): 336-42. doi: 0141705/AIM.006. PMID: 24784862.

4) Hatmi ZN, Tahvildari S, Motlag AG, Kashani AS. Prevalence of coronary artery disease risk factors in Iran: a population based survey. BMC cardiovascular disorders. 2007; 7(1): 32. doi: 10.1186/1471-2261-732.

5) WHO. Cardiovascular diseases (CVDs), Fact sheets. 2016. Available from: http://www.who.int/mediacentre/factsheets/fs317/en/

6) Yusuf S, Reddy S, Ônpuu S, Anand S. Global burden of cardiovascular diseases part I: general considerations, the epidemiologic transition, risk factors, and impact of urbanization. Circulation. 2001; 104(22): 2746-53.

7) Abegunde DO, Mathers CD, Adam T, Ortegon M, Strong K. The burden and costs of chronic diseases in low-income and middle-income countries. The Lancet. 2007; 370(9603): 1929-38. doi: 10.1016/S01406736(07)61696-1.

8) Parmley WW. Nonlipoprotein risk factors for coronary heart disease: evaluation and management. Am J Med. 1997; 102 (2A): 7-14. doi: 10.1016/S0002-9343(97)00461-0.

9) Corti MC, Guralnik JM, Bilato C. Coronary heart disease risk factors in older persons. Aging (Milano). 1996; 8(2): 75-89.

10) Castelli WP, Wilson PW, Levy D, Anderson K. Cardiovascular risk factors in the elderly. Am J Cardiol. 1989; 63: 16. doi: 10.1080/22201009.2012.10872272.

11) Toutouzas PK. Gender differences on the risk evaluation of acute coronary syndromes: the CARDIO2000 study. Prev Cardiol. 2003, 6: (2): 71-7. doi: 10.1111/j.1520-037X.2003.01609.x.

12) Bittner V. Women and coronary heart disease risk factors. J Cardiovasc Risk. 2002; 9: 315-22. doi: $10.3109 / 13697130903276422$.

13) Sasaki S, Nakamura K, Uchida A, Fujita H, Itoh H, Nakata T, et al. Blood pressure at health screening as a predictor of coronary heartdisease in Kyoto. J Cardiovasc Risk. 1996; 3:(1): 77-82. doi: 10.1177/174182679600300111. PMID: 8783034.

14) Basile JN. Hypertension 2001: pearls for the clinician. South Med J. 2001; 94: 111054-7. PMID: 11780673.

15) Laws A, Reaven GM. Insulin resistance and risk factors for coronary heart disease. Baillieres Clin Endocrinol Metab. 1993; 7: 1063-78. doi: 10.1016/S0950-351X(05)80245-9.

16) Haffner SM. Epidemiology of insulin resistance and its relation to coronary artery disease. Am J Cardiol. 1999; 84: 11-4. doi: 10.1016/S0002-9149(99)00351-3.

17) Adamopoulos PN, Macrilakis K, Papamichael C, Malakos I, Panayidis N, Moulopoulos SD. Physical activity and relationship with coronary heart disease risk factors. Acta Cardiol. 1993; 48(6): 523-34. PMID: 8122476.

18) Milei J, Grana DR. Mortality and morbidity from smoking- induced cardiovascular disease: The necessity ofthe cardiologist's involvement and commitment. Int J cardiology. 1998; 67: 95-109. doi: 10.1016/S01675273(98)00248-4. PMID: 9891942.

19) Boffetta P, Straif K. Use of smokeless tobacco and risk of myocardial infarction and stroke: systematic review with meta-analysis. BMJ. 2009; 339: b3060. doi: 10.1136/bmj.b3060. PMID: 19690343, PMCID: PMC2728803.

20) Teo KK, Ounpuu S, Hawken S, Pandey MR, Valentin V, Hunt D, et al. Tobacco use and risk of myocardial infarction in 52 countries in the INTERHEART study: a case-control study. Lancet. 2006; 368: 647-58. doi: 10.1016/S0140-6736(06)69249-0. PMID: 16920470. 
21) Marshall MR, Ghazipura M, Hossain T, Gordon T, Chen LC. Cardiopulmonary Risk of Waterpipe Smoke: A Meta-Analysis. Journal of lung Health and Disease. 2018.

22) Rahmani M, Raiszadeh F, Allahverdian S, Kiaii Sh, Navab M, Azizi F. Coronary artery disease is associated with the ratio of apolipoprotein A-I/B and serum concentration of apolipoprotein B, but not with paraoxonase enzyme activity in Iranian subjects. Atherosclerosis. 2002; 162: 381-9. doi: 10.1016/S00219150(01)00715-8.

23) Haidari M, Moghadam M, Chinicar M, Ahmadieh A, Doosti M. Apolipoprotein B as the best predictor of coronary artery disease in Iranian normolipidemic patients. Clin Biochem. 2001; 34: 149-55. doi: 10.1016/S0009-9120(01)00192-8.

24) Rasouli M, Kiasari AM. Interactions of serum hsCRP with apoB, apoB/AI ratio and some components of metabolic syndrome amplify the predictive values for coronary artery disease. Clinical biochemistry. 2006; 39(10): 971-7. doi: 10.1016/j.clinbiochem.2006.07.003.

25) Thayer JF, Yamamoto SS, Brosschot JF. The relationship of autonomic imbalance, heart rate variability and cardiovascular disease risk factors. International journal of cardiology. 2010; 141(2): 122-31. doi: 10.1016/j.ijcard.2009.09.543.

26) WHO. Noncommunicable Diseases (NCD) Country Profiles. Iran (Islamic Republic of). Available from: http://www.who.int/nmh/countries/irn_en.pdf?ua=1

27) Mahmood SS, Levy D, Vasan RS, Wang TJ. The Framingham Heart Study and the epidemiology of cardiovascular disease: a historical perspective. Lancet. 2013; 383(9921): 999-1008. doi: 10.1016/S01406736(13)61752-3. PMID: 24084292, PMCID: PMC4159698.

28) D'agostino RB, Vasan RS, Pencina MJ, Wolf PA, Cobain M, Massaro JM, Kannel WB. General cardiovascular risk profile for use in primary care. Circulation. 2008; 117(6): 743-53. doi: 10.1161/CIRCULATIONAHA.107.699579. PMID: 18212285.

29) Grundy SM, Pasternak R, Greenland P, Smith S, Fuster V. Assessment of cardiovascular risk by use of multiple-risk-factor assessment equations: a statement for healthcare professionals from the American Heart Association and the American College of Cardiology. Journal of the American College of Cardiology. 1999; 34(4): 1348-59. doi: 10.1016/S0735-1097(99)00387-3.

30) Ichler K, Puhan MA, Steurer J, Bachmann LM. Prediction of first coronary events with the Framingham score: a systematic review. Am Heart J. 2007; 153(5): 722-31. doi: 10.1016/j.ahj.2007.02.027. PMID: 17452145 .

31) Bozorgmanesh M, Hadaegh F, Azizi F. Predictive accuracy of the 'Framingham's general CVD algorithm'in a Middle Eastern population: Tehran Lipid and Glucose Study. International journal of clinical practice. 2011; 65(3): 264-73. doi: 10.1111/j.1742-1241.2010.02529. PMID: 21314863.

32) Yusuf S, Reddy S, Ôunpuu S, Anand S. Global burden of cardiovascular diseases: Part II: variations in cardiovascular disease by specific ethnic groups and geographic regions and prevention strategies. Circulation. 2001; 104(23): 2855-64. doi: 10.1161/circ.104.23.2855. PMID: 11733407.

33) Selvarajah S, Kaur G, Haniff J, Cheong KC, Hiong TG, van der Graaf Y, et al. Comparison of the Framingham Risk Score, SCORE and WHO/ISH cardiovascular risk prediction models in an Asian population. International journal of cardiology. 2014; 176(1): 211-8. doi: 10.1016/j.ijcard.2014.07.066.

34) Meysamie A, Salarvand F, Khorasanizadeh M, Ghalehtaki R, Eskian M, Ghodsi S, et al. Cardiovascular risk assessment by FRS and SCORE in Iranian adult population. Journal of Diabetes \& Metabolic Disorders. 2017; 16(1): 35. doi: 10.1186/s40200-017-0316-4.

35) Sarrafzadegan N, Hassannejad R, Marateb HR, Talaei M, Sadeghi M, Roohafza HR, et al. PARS risk charts: A 10-year study of risk assessment for cardiovascular diseases in Eastern Mediterranean Region. PloS One. 2017; 12(12): e0189389. doi: 10.1371/journal.pone.0189389. PMID: 29261727.

36) Hosseinkhani Z, Ziaee A, Ghorbani A, Javadi A. Distribution of Cardiovascular Disease (CVD) Risk Factors in Adults in Qazvin City. Medical journal of Mashhad University of Medical Sciences. 2013; 56(5): 275-82.

37) Nasehi MM, Moosazadeh M, Amiresmaeili M, Zakizadeh R, Mirzajani M. Prevalence of five main risk factors of non-communicable diseases in Mazandaran province: a population based study. Journal of Mazandaran University of Medical Sciences. 2012; 21(86): 193-202.

38) Fariba F, Ashari FE, Moradi M. Comparison of Risk Factors Frequency in Patients with ST-elevation MI \& Patients with Non ST-elevation MI in Hamadan City. Scientific Journal of Hamadan University of Medical Sciences. 2015; 22(1): 11-5. 
39) Tattersall MC, Gangnon RE, Keevil JG. Women Up, Men Down: The Clinical Impact of Replacing the Framingham Risk Score With the Reynolds Risk Score in the United States Population. doi: 10.1371/journal.pone.0044347.

40) Chaves G, Britez N, Munzinger J, Uhlmann L, Gonzalez G, Oviedo G, et al. Education to a healthy lifestyle improves symptoms and cardiovascular risk factors-AsuRiesgo Study. Arquivos brasileiros de cardiologia. 2015; 104(5): 347-55. doi: 10.5935/abc.20150021.

41) Azizi F, Rahmani M, Emami H, Mirmiran PA, Hajipour R, Madjid M, et al. Cardiovascular risk factors in an Iranian urban population: Tehran lipid and glucose study (phase 1). Sozial-und präventivmedizin. 2002; 47(6): 408-26. doi: 10.1007/s000380200008. PMID: 12643001.

42) Rasouli M, Mohseni Kiasari A, Mokhberi V, Bagheri B, Daneshpour N, Shariati R, et al. Global risk assessment of coronary heart disease using Framingham's scores for major risk factors. Mazandaran Univ Med Sci. 2006; 15(50): 49-62.

43) Sarrafzadegan N, Alikhasi Abda N. Cardiovascular disease situation and-preventive action in Iran. Intern Symp Ather. 1997; F025

44) Toutouzas PK. Gender differences on the risk evaluation of acute coronary syndromes: the CARDIO2000 study Prev Cardiol. 2003; 6(2): 71-7.

45) Bittner V. Women and coronary heart disease risk factors. J Cardiovasc Risk. 2002; 9: 315-22. doi: 10.1111/j.1520-037X.2003.01609. PMID: 12478200.

46) Tan YY. Gast GC, van der Schouw YT. Gender differences in risk factors for coronary heart disease. Maturitas. 2010; 65: 149-160. doi: 10.1016/j.maturitas.2009.09.023.

47) Kubota Y, Heiss G, MacLehose RF, Roetker NS, Folsom AR. Association of Educational Attainment With Lifetime Risk of Cardiovascular Disease: The Atherosclerosis Risk in Communities Study. JAMA Intern Med. 2017; 177(8): 1165-72. doi: 10.1001/jamainternmed.2017.1877. PMID: 28604921, PMCID: PMC5710437.

48) Goda A, Demiraj AF, Weidinger F, Metzler B, Ibrahimov F, Pasquet AA, et al. European Society of Cardiology: cardiovascular disease statistics 2017. European heart journal. 2017. doi: 10.1093/eurheartj/ehx628.

49) Eaker, ED. Psychosocial risk factors for coronary heart disease in women. Cardiology Clinic. 1998; 16: 103-11. PMID: 9507784.

50) Herlitz J, Aune S, Claesson A, Svensson L. Epidemiology of cardiac arrest outside and inside hospital Experiences from registries in Sweden. Signa vitae. 2010; 5(Suppl 1): 44-5.

51) Ikeda A, Iso H, Toyoshima H, Fujino $Y$, Mizoue $T$, Yoshimura $T$. Marital status and mortality among Japanese men and women: the Japan collaborative cohort study. BMC Public Health. 2007; 7: 73. doi: 10.1186/1471-2458-7-73. PMID: 17484786, PMCID: PMC1871578. 